\title{
Repensando o Processo de Aprendizagem Organizacional no Agronegócio: um Estudo de Caso realizado numa Cooperativa Destaque em Qualidade no RS
}

\author{
Vania de Fátima Barros Estivalete \\ Mauri Leodir Löbler \\ Eugênio Ávila Pedrozo
}

\begin{abstract}
Resumo
O presente artigo tem como objetivo investigar os estilos de aprendizagem gerencial sob a perspectiva de Kolb (1978) e verificar se há relação entre os estilos de aprendizagem e os Motivos Sociais propostos por McClelland (1972). A estratégia metodológica utilizada foi o estudo de caso realizado em uma Cooperativa localizada no interior do Estado do Rio Grande do Sul, destaque em qualidade na região. Os sujeitos da pesquisa são em número de 11, incluindo-se o presidente, a gerência de Recursos Humanos e os gerentes das unidades de negócios que fazem parte do Comitê Gestor da Qualidade. A coleta dos dados foi baseada em fontes documentais, questionários e entrevistas individuais semi-estruturadas. Constatou-se que os gerentes possuidores dos estilos de aprendizagem convergente e acomodador sentem uma maior necessidade de poder, revelando uma necessidade menor de realização. Em contraposição, verificou-se que os possuidores dos estilos divergente e assimilador sentem maior necessidade de realização e menor necessidade de poder. Dada a complexidade do comportamento humano, entende-se que a classificação dos gestores de acordo com determinados estilos e motivos sociais não deve ser considerada de maneira estanque e definitiva, mas como forma de compreendê-lo melhor.
\end{abstract}

Palavras-chave: aprendizagem organizacional; estilo de aprendizagem gerencial; motivos sociais.

\begin{abstract}
The objective of this article is to investigate the managerial learning styles as seen by Kolb (1978) and verify whether there is any relationship between learning styles and the Social Motives proposed by McClelland (1972). The strategic methodology used was the case study conducted in a top quality Cooperative located in the interior of Rio Grande do Sul, Brazil. The subjects of the research are 11, including the president, the Human Resources management and the managers of the business unities composing the Quality Management Committee. The data collection was based on questionnaires and semi-structured individual interviews. It was verified that managers with convergent and accommodative learning styles feel a higher need for power than for achievement. On the other hand, it was demonstrated that those with divergent and assimilative styles express a higher need for achievement than for power. Given the complexity of human behavior, the classification of administrators according to certain social styles and motives should not be viewed as something stagnant and definitive, but rather as a way of facilitating comprehension.
\end{abstract}

Key words: organizational learning; managerial learning styles ; social motives. 


\section{INTRODUÇÃO}

As organizações pertencentes ao setor agronegocial inserem-se num cenário de crescente competitividade, o que as obriga a buscar meios e ações estratégicas que permitam garantir a sua sobrevivência e continuidade. Desta forma, as organizações cooperativas agropecuárias encontram-se inseridas neste contexto, uma vez que convivem com um duplo desafio - social e econômico (Pedrozo \& Silva, 1999) - que têm provocado a necessidade de rever paradigmas de gestão e introduzir novas práticas de aprendizagem, alinhadas às exigências do mundo contemporâneo.

Partindo-se do pressuposto de que o processo de aprendizagem organizacional constitui fonte de vantagem competitiva, torna-se essencial para as organizações cooperativas a presença de profissionais dispostos a aprender a aprender e disponibilizar o aprendizado a outras pessoas que fazem parte da organização, resultando em um ambiente organizacional propício ao aprendizado, possibilitando que estas organizações se posicionem estrategicamente em diferentes momentos de sua trajetória.

Nesse sentido, ao tratar-se de uma organização cooperativa para que o aprendizado realmente ocorra, torna-se relevante o conhecimento dos estilos de aprendizagem dos gestores e a forma de gerenciamento do processo de aprendizagem dos colaboradores por meio da criação de um clima propício ao aprendizado. Um dos grandes desafios das organizações do futuro é o de saber usar o conhecimento de cada um, saber somá-los e saber criar um ambiente de sinergia para alavancar os negócios da organização (Romani \& Dazzi, 2002). Assim, a partir desses pressupostos, alguns questionamentos podem ser feitos: como ocorre o processo de aprendizagem em uma organização do setor de agronegócios e quais os estilos de aprendizagem dos seus gestores? Existe relação entre os estilos de aprendizagem dos gerentes e os motivos sociais de afiliação, realização e poder propostos por McClelland? Como repensar o processo de aprendizagem à luz dessas questões de modo que se possa instituir uma cultura de aprendizagem na organização investigada?

Com base nessas indagações, este estudo tem como objetivo investigar, em uma organização cooperativa, os estilos de aprendizagem gerencial sob a perspectiva de Kolb (1978) e verificar se há relação entre esses estilos e os Motivos Sociais propostos por McClelland (1972). Este estudo apresenta um caráter exploratório, pois tem a função de lançar luz sobre certos aspectos do 
fenômeno estudado (Quivy \& Campenhoudt, 1992) e buscar nova forma de abordar o tema proposto, formulando-se hipóteses pesquisáveis para estudos posteriores.

\section{Base Conceitual: um Recorte Teórico}

Essa seção apresenta uma breve fundamentação teórica, revisitando as principais contribuições sobre Aprendizagem Organizacional, destacando-se os Estilos de Aprendizagem Gerencial sob a perspectiva de Kolb (1978) e os Motivos Sociais de Afiliação, Realização e Poder desenvolvidos por McClelland (1972).

\section{Aprendizagem Organizacional}

A busca da excelência empresarial tem sido perseguida, incessantemente, pelas organizações e pelos profissionais que nela trabalham e isso não se consegue apenas pelo bom desempenho na execução das atividades, mas por meio da capacidade de adaptação às mudanças que são impostas e, principalmente, pela busca constante de novas abordagens administrativas, novos sistemas de gestão com foco no ser humano e novos conhecimentos.

Reforça-se, desse modo, a importância da aprendizagem nas organizações, destacando-se a contribuição de Senge (1998), ao salientar que o ser humano vem ao mundo motivado a aprender e experimentar. Infelizmente, a grande maioria das organizações é mais orientada para controlar do que para aprender, recompensando o desempenho das pessoas em função da obediência a padrões estabelecidos e não por seu desejo de aprender.

Na concepção de Fleury e Fleury (1997, p. 20):

O processo de aprendizagem em uma organização não só envolve a elaboração de novos mapas cognitivos, que permitem compreender melhor o que está ocorrendo em seu ambiente externo e interno, como também a definição de novos comportamentos, que comprovam a efetividade do aprendizado.

Dando continuidade ao seu pensamento, Fleury e Fleury (1997, p. 222) defendem alguns pressupostos que orientariam as empresas e dariam sustentação ao processo de aprendizagem, dentre os quais se destaca: pensamento sistemático, ação estratégica, integração dos processos de decisão, definição de políticas de RH que sustentem e impulsionem a aprendizagem e, fundamentalmente, o desenvolvimento de uma cultura de aprendizagem. Schein (1996) trabalha nessa 
linha, enfatizando a construção de uma cultura de aprendizagem nas organizações, sendo essa tanto conseqüência das experiências e aprendizagem quanto base para sua capacidade para o aprendizado contínuo. Para desenvolver essa cultura, os autores enfatizam que as organizações necessitam apoiar-se nas pessoas, uma vez que elas constituem a base do processo.

Segundo o pensamento de Boyett e Boyett (1999), o aprendizado do indivíduo é condição necessária mas não suficiente para a inteligência organizacional. O fator crucial reside na eficácia com que os indivíduos transferem o que sabem para a organização como um todo.

Os autores Caravantes e Pereira (1985, p. 6) definem a aprendizagem como "o processo de aquisição da capacidade de usar o conhecimento, que ocorre como resultado da prática e da experiência crítica e que produz uma mudança relativamente permanente no comportamento". Esta definição em muito se assemelha à de Garvin (1993) que destaca: "as organizações que aprendem devem estar capacitadas a criar, adquirir e transferir conhecimentos e em modificar seus comportamentos para refletir estes novos conhecimentos e insight".

Na percepção de Kolb (1997), a aprendizagem constitui-se num processo em que o conhecimento é criado por meio da experiência. Esse autor considera o modelo de como as pessoas aprendem, denominado de modelo vivencial, como um ciclo quadrifásico composto de quatro tipos de habilidades: experiência concreta, observação reflexiva, conceituação abstrata e experimentação ativa. Assim, vem à tona o seguinte questionamento: Como as pessoas aprendem e como ocorre a transferência daquilo que elas sabem para que a organização também possa aprender?

Em face dos questionamentos mencionados na introdução deste artigo, convém ressaltar a concepção de Kim (1998), ao salientar que, nos estágios iniciais de uma organização, a aprendizagem individual se confunde com a organizacional, pelo fato de a empresa ser constituída por um número restrito de pessoas e por possuir uma estrutura pequena. Com o crescimento da empresa, esta distinção vai tornando-se mais clara, uma vez que a organização é afetada pelo aprendizado individual de seus membros. Embora possa existir esta confusão entre a aprendizagem individual e organizacional, a aprendizagem organizacional, segundo os autores, é mais do que a simples soma das aprendizagens dos indivíduos. Sweringa e Wierdsma (1995) salientam que a aprendizagem individual é necessária, mas não suficiente para o aprendizado coletivo.

Vinculada a esta questão, focaliza-se o processo de aprendizagem organizacional, que apesar de ser uma abordagem relativamente recente, já existem diferentes concepções a respeito deste tema. Destaca-se o estudo de Argyris e Schön (1978) 
sobre aprendizagem de single loop (ciclo único) e doble loop (ciclo duplo). A aprendizagem de ciclo único refere-se ao como fazer as coisas melhor por meio da experiência e exerce impacto sobre parte da organização. A segunda foca o porquê das coisas serem feitas, gera efeitos e impactos de longo prazo, referese a mudanças mais radicais e tem como objetivo o desenvolvimento de novos paradigmas, envolvendo o questionamento dos valores fundamentais da organização.

Segundo a visão dos autores Sweringa e Wierdsma (1995), o processo de aprendizagem passa por três ciclos: regras, insights e princípios. As regras referemse ao que se deve e pode fazer. Os insights ao que se sabe, ao que se compreende e os princípios ao que se é e ao que se deseja ser. Então, a aprendizagem de três ciclos acontece quando ocorre o questionamento e discussão dos princípios essenciais sobre os quais a empresa está alicerçada.

Para Senge (1998, p. 37) as organizações que aprendem: "São organizações nas quais as pessoas expandem continuamente sua capacidade de criar resultados que realmente desejam, onde se estimulam padrões de pensamentos novos e abrangentes, a aspiração coletiva ganha liberdade e onde as pessoas aprendem continuamente a aprender juntas".

As organizações orientadas para a aprendizagem, segundo Morgan (1996), devem seguir quatro diretrizes básicas: flexibilidade, análise e solução de problemas, ação para investigação e a realização de intervenções. Já Bernardes (1999) construiu um modelo de aprendizagem organizacional baseado na contribuição de diversos autores. As dimensões de uma Learning Organization na visão da autora contemplam: democratização das informações, objetivo compartilhado, ambiente que incentive a aprendizagem, visão sistêmica e ação monitorada. Esse modelo é semelhante ao proposto por Senge (1990), que apresenta como pressupostos básicos para a aprendizagem organizacional a incorporação de cinco disciplinas que as organizações que aprendem devem assimilar: domínio pessoal, modelos mentais, objetivo comum, aprendizado em grupo e raciocínio sistêmico.

Como se vê, a aprendizagem organizacional é algo complexo que apresenta focos divergentes de estudo; porém, no campo das organizações, a aprendizagem organizacionalé vista como alavancadora da competitividade e inovação (Dodgson, 1993, p. 376). Ao refletirmos sobre as diversas concepções que existem sobre aprendizagem organizacional, retomam-se os questionamentos anteriormente mencionados. As organizações estão capacitadas a criar, adquirir uma cultura de aprendizagem? Os estilos de aprendizagem dos gerentes podem facilitar esse processo? A fim de buscar respostas às indagações efetuadas, este estudo propõe- 
se a identificar os estilos de aprendizagem gerencial e a sua inter-relação com as necessidades humanas de realização, afiliação e poder, de modo que se possa repensar o processo de aprendizagem organizacional.

\section{Estilos de Aprendizagem Gerencial}

Os gestores desenvolvem estilos de aprendizagem diferenciados em função de suas características pessoais, sua experiência profissional, sua personalidade, seu modo de viver e, também em função do ambiente em que se inserem, priorizando determinados aspectos no processo de aprendizagem. Por sua vez, cada pessoa desenvolve sua própria maneira de aprender, seu estilo próprio de aprendizagem, que combina com sua visão de mundo, seu modelo mental e com seu modo de ser, pensar e agir.

Antonacopoulou (2001) destaca que a pesquisa de aprendizagem no âmbito das organizações está perdendo de vista a importância das pessoas como a chave para desvendar muito mistério ao redor da aprendizagem. Salienta que a aprendizagem é uma das atividades humanas mais proeminentes ao proporcionar insights valiosos sobre os fatores que facilitam ou inibem a aprendizagem no interior das organizações, assim como as conseqüências da aprendizagem individual (ou a sua falta) para a organização. Esses aspectos enfatizam a importância do desenvolvimento de habilidades, conhecimentos e atitudes nos atores responsáveis pela condução e gestão dos negócios no sentido de resolver problemas, experimentar novas tecnologias, aprender mais com base em experiências, observando o comportamento de outros, além de aprender, transmitir e compartilhar o conhecimento com os demais envolvidos no processo.

Os autores Swieringa e Wierdsma (1995) postulam que o aprendizado pode ser considerado uma competência relacionada ao aprender a aprender e a mudança de comportamento como uma demonstração do aprendizado individual. Reforça-se, entretanto, a importância da aprendizagem individual e dos estilos de aprendizagem no processo de aprendizagem organizacional, uma vez que esta ocorre por meio da aprendizagem das pessoas que a compõem. Esse ponto sinaliza a necessidade de um melhor entendimento sobre a interação do indivíduo com a organização no que se refere ao processo de aprendizagem. Assim, para melhor compreensão apresenta-se a contribuição de Kolb (1997) que, baseandose nos trabalhos de Kurt Lewin, analisou os estilos de aprendizagem individual no campo das organizações, desenvolvendo o Inventário de Estilo de Aprendizagem, no sentido de auxiliar na identificação do estilo de aprendizagem de cada pessoa. O inventário, desenvolvido por esse autor, contempla quatro modos de aprendizagem que são apresentados no Quadro 1, bem como suas características e dimensões. 


\section{Quadro 1: Estilos de Aprendizagem e Características}

\begin{tabular}{|c|c|c|}
\hline Estilos & Características & Dimensões \\
\hline Convergente & $\begin{array}{l}\text { Aplicação prática de idéias; } \\
\text { Raciocínio hipotético-dedutivo; } \\
\text { Tendem a ser técnicos específicos. }\end{array}$ & $\begin{array}{c}\text { Experimentação Ativa } \\
\text { e } \\
\text { Conceituação Abstrata }\end{array}$ \\
\hline Divergente & $\begin{array}{l}\text { Capacidade de Imaginação; } \\
\text { Pessoas imaginativas e emotivas; } \\
\text { Identificação de problemas e busca de } \\
\text { soluções analisando a realidade. }\end{array}$ & $\begin{array}{l}\text { Experiência Concreta } \\
\text { e } \\
\text { Observação Reflexiva }\end{array}$ \\
\hline Assimilador & $\begin{array}{l}\text { Capacidade de criar modelos teóricos; } \\
\text { Preocupação com conceitos abstratos; } \\
\text { Raciocínio indutivo; } \\
\text { Importância para teorias precisas e sólidas. }\end{array}$ & $\begin{array}{l}\text { Conceituação Abstrata } \\
\text { e } \\
\text { Observação Reflexiva }\end{array}$ \\
\hline Acomodador & $\begin{array}{l}\text { Valoriza a realização, execução e } \\
\text { experimentação; } \\
\text { Facilidade na adaptação a circunstâncias } \\
\text { imediatas específicas; } \\
\text { Gostam de estar com pessoas. }\end{array}$ & $\begin{array}{l}\text { Experiência Concreta } \\
\text { e } \\
\text { Experimentação Ativa }\end{array}$ \\
\hline
\end{tabular}

Fonte: elaborado com base em Kolb (1997); Nakayama, Binotto e Estivalete (2002).

Kolb (1997) desenvolveu um modelo para explicar como ocorre o processo de aprendizagem por meio de um ciclo quadrifásico, denominado de modelo vivencial, conforme pode ser visualizado na Figura 1, onde a experiência concreta imediata é a base da observação e da reflexão. Segundo o autor, para que o aprendizado realmente se efetive, as pessoas necessitam desenvolver quatro tipos diferentes de habilidades: experiência concreta, observação reflexiva, conceituação abstrata e experimentação ativa, que combinadas dão origem a quatro estilos de aprendizagem: convergente, divergente, acomodador e assimilador.

\section{Figura 1: Estilos de Aprendizagem e Características}

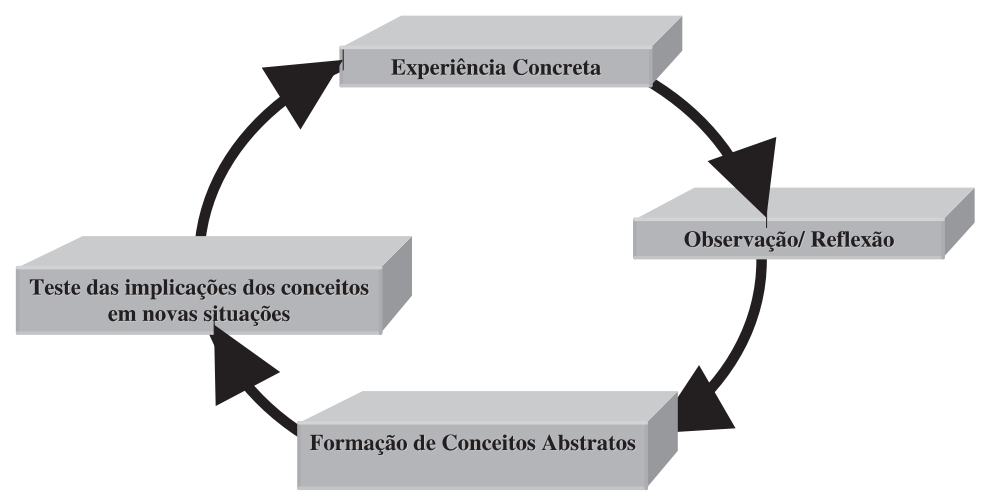

Fonte: elaborado com base em Kolb (1997); Nakayama et al. (2002). 
O ciclo apresentado na Figura 1 possibilita a visualização das duas dimensões básicas no processo de aprendizagem: uma que representa a experiência concreta de eventos, de um lado e a conceituação abstrata, do outro; e a outra que representa a experiência ativa, de um lado e a experimentação reflexiva, do outro (Kolb, 1997). Em estudo realizado por Nakayama et al. (2002) em uma organização brasileira do setor de serviços que atua no ramo de administração de estacionamentos, os estilos de aprendizagem dos gestores entrevistados se manifestaram de forma eqüitativa, englobando três categorias: divergente, convergente e acomodador. Não foi evidenciado no estudo a presença do estilo assimilador entre os entrevistados. Assim, percebe-se que o ato de aprender exige habilidades variadas, complementares e opostas, que variam do concreto ao abstrato, do ativo ao reflexivo que servem como orientação ao aprendiz sobre quais habilidades deve procurar desenvolver em cada situação de aprendizagem.

\section{Os Motivos Sociais de McClelland}

A teoria de necessidades ou os motivos sociais de McClelland enfoca três motivos que impactam no estilo gerencial e na forma como os gestores aprendem e transferem aquilo que sabem, para que a organização e seus membros também possam aprender. São eles: necessidade ou motivo de realização, de afiliação e de poder.

O motivo de realização leva as pessoas a assumirem responsabilidades, adotarem altos padrões de desempenho e fixarem com clareza os objetivos que desejam alcançar (Kolb, Rubin, \& Mcintyre, 1978).

Segundo Robbins (1999), indivíduos altamente realizadores têm impulso forte de ter sucesso e se esforçam pela realização pessoal mais do que pelas recompensas do sucesso em si. Estas pessoas têm desejo de fazer algo melhor ou mais eficientemente do que foi feito antes. As pesquisas realizadas sobre a necessidade de realização revelaram que as pessoas não gostam de ter sucesso ao acaso. Preferem o desafio de trabalhar num problema e aceitar a responsabilidade pessoal pelo seu sucesso ou fracasso. Querem vencer obstáculos, mas querem sentir que seu sucesso é resultado de suas próprias ações (Robbins, 1999).

O motivo de afiliação leva as pessoas a procurarem reconhecimento, calor humano e apoio. "As necessidades de relacionamento, de pertencer, de intimidade, de amor e de afeição são de grande importância para os seres humanos e podem, em determinado momento, ser preponderantes, impedindo a emergência de outras necessidades" (Aguiar, 1988). 
Para Robbins (1999) indivíduos com alta motivação de afiliação lutam por amizades, preferem situações de cooperação em vez de competição e desejam relacionamentos que envolvam alto grau de compreensão mútua.

O motivo de poder leva as pessoas a valorizarem a autoridade (normas e líderes), quer como chefes quer como subordinados, assim como caracteriza o desejo das pessoas de exercerem poder e influência sobre os outros. Estabelecem como metas e objetivos pessoais a obtenção de poder e de status (Souza, 1978).

Na concepção de Robbins (1999), indivíduos com alta necessidade de poder apreciam estar no controle, lutam para ter influência sobre os outros, preferem ser colocados em situações competitivas e tendem a ser mais preocupados com prestígio e a ter influência sobre os outros do que com um desempenho eficaz.

\section{Método e Procedimentos}

O problema de pesquisa verifica a relação entre dois pontos essenciais: os estilos de aprendizagem gerencial que trazem implicações relevantes quanto ao modo como as pessoas aprendem e como transferem o conhecimento para que a organização também possa aprender, e a relação com os Motivos Sociais, propostos por McClelland, de realização, afiliação e poder. Esses pontos serviram de orientação básica para definir a problemática dessa pesquisa que consiste na seguinte questão: de que modo se pode repensar o processo de aprendizagem em uma organização cooperativa, à luz da relação entre os estilos de aprendizagem de seus gestores e os Motivos Sociais de realização, afiliação e poder?

A estratégia de pesquisa adotada para este estudo pode ser classificada como exploratória que, segundo Gil (1999), tem como principal finalidade desenvolver, esclarecer e modificar conceitos e idéias, tendo em vista a formulação de problemas mais precisos ou hipóteses pesquisáveis para estudos posteriores. Para melhor compreensão a Figura 2 apresenta uma síntese do modelo de pesquisa realizado neste estudo. 
Figura 2: Modelo de Pesquisa - Verificação de Relações entre Estilos de Aprendizagem Gerencial e Motivos Sociais de McClelland

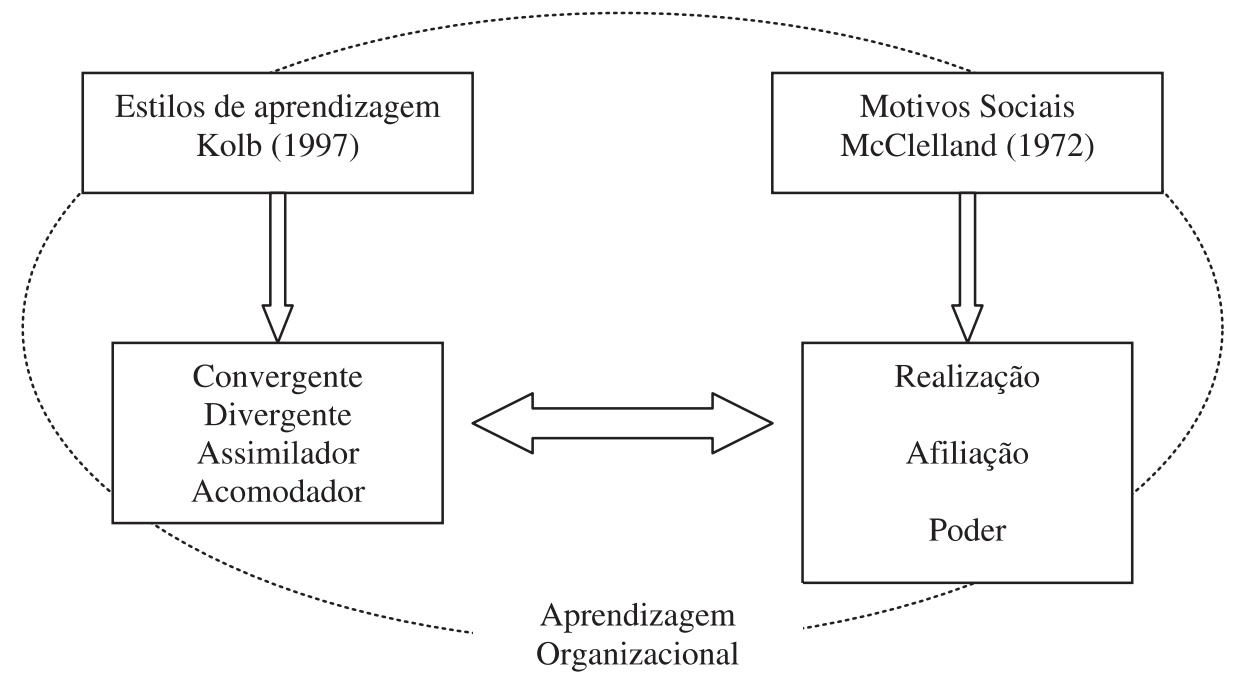

O método adotado para o desenvolvimento dessa pesquisa é o do estudo de caso que, segundo Yin (2001, p. 32), "investiga um fenômeno contemporâneo dentro de seu contexto da vida real, especialmente quando os limites entre o fenômeno e o contexto não estão claramente definidos".

A organização, objeto desse estudo, foi uma Cooperativa localizada no interior do Estado do Rio Grande do Sul, destaque em qualidade na região. A escolha do local do estudo deve-se ao fato de ela ser pioneira no município a participar do Programa Gaúcho de Qualidade e Produtividade (PGQP) e por ser uma das organizações do setor agronegocial a receber o Prêmio Qualidade RS.

Os sujeitos da pesquisa são em número de 11, incluindo-se o presidente, a gerência de Recursos Humanos e os gerentes das unidades de negócios, que também fazem parte do Comitê Gestor da Qualidade. O perfil predominante dos entrevistados é, em sua grande maioria, de casados (82\%); acima de 35 anos de idade (63\%); sexo masculino (73\%); segundo grau completo e curso profissionalizante (63\%); e possuem acima de 10 anos de empresa (63\%).

A coleta dos dados ocorreu em quatro etapas. Para identificação dos estilos de aprendizagem utilizou-se o Inventário de Estilo de Aprendizagem gerencial, desenvolvido por Kolb (1978), constando de quatro estilos: divergente, convergente, acomodador e assimilador. Num segundo momento, aplicou-se um questionário aos gestores no sentido de identificar os motivos sociais que impactam na forma de aprender, desenvolvido com base em McClelland (1972) que são: afiliação, 
realização e poder. O questionário constou de questões fechadas, utilizando-se uma escala Likert de 0 a 7 pontos, sendo que o 0 representa que determinado motivo social não impacta a aprendizagem do gestor e o 7 que a impacta fortemente. No lado esquerdo de cada questão os respondentes assinalavam a situação real (atual) e no lado direito a situação considerada ideal pelos entrevistados. Num terceiro momento, foram realizadas entrevistas individuais em profundidade que foram gravadas e, logo após, transcritas com a permissão dos entrevistados. A transcrição das entrevistas foi revisada pelos pesquisadores, constituindo-se em dados de análise. Por último, foi realizada a pesquisa documental por meio de subsídios oferecidos pela cooperativa como: relatório desenvolvido para inscrição Prêmio Qualidade RS, material sobre os produtos que a cooperativa comercializa e folders institucionais.

A análise dos dados foi feita quantitativamente por meio da utilização do software sphinx e qualitativamente à luz do referencial teórico utilizado nesse estudo, tomando-se como material de análise os documentos que foram disponibilizados, as informações constantes dos questionários e as transcrições das entrevistas. No aspecto quantitativo foram calculadas as médias real e ideal para cada um dos motivos sociais existentes, sendo após realizado o teste " $\mathrm{t}$ " de Student para testar as diferenças das médias. Decidiu-se pela aplicação desse teste pelo fato de que ele é adequado para verificar as diferenças de médias entre amostras emparelhadas, ou seja, os dois conjuntos de observações estão relacionados aos mesmos respondentes. Na aplicação do teste " $t$ " de Student procurou-se verificar se existe realmente diferença entre as médias, considerando um nível de significância de $\alpha=5 \%$.

\section{Discussão e Análise dos Resultados}

Esta seção apresenta a análise e discussão dos resultados da pesquisa realizada, apresentando os estilos de aprendizagem dos gestores da cooperativa investigada, a média dos motivos sociais de McClelland (1972) e o estabelecimento de uma hipotética relação entre os estilos de aprendizagem e os motivos sociais de realização, afiliação e poder.

Para calcular a média real e a ideal, utilizaram-se as notas atribuídas às questões do instrumento de coleta de dados, envolvendo os motivos sociais estudados. Após calculou-se a diferença entre a média real e a ideal. As médias da situação real e ideal foram calculadas a partir do agrupamento das questões de acordo com os motivos sociais propostos por McClelland (1972). 


\section{Estilos de Aprendizagem dos Gestores}

O esquema conceitual desenvolvido por Kolb (1978, p. 36) serviu de base para a identificação dos estilos de aprendizagem dos gerentes entrevistados. Este mesmo autor desenvolveu um inventário de estilo de aprendizagem, contemplando quatro dimensões: Experiência Concreta, Observação Reflexiva, Conceitualização Abstrata e Experimentação Ativa, que representam os estágios do processo de aprendizagem, originando quatro diferentes estilos que são: Divergente, Convergente, Acomodador e Assimilador.

Mediante a aplicação desse inventário, os sujeitos entrevistados revelaram possuir estilos de aprendizagem diferenciados, predominando o estilo convergente em quatro dos onze gerentes investigados. $\mathrm{O}$ estilo acomodador manifestou-se em três gerentes e os estilos divergente e assimilador manifestaram-se de forma eqüitativa, sendo que dois dos entrevistados se enquadraram no estilo divergente e dois no estilo assimilador. Para aprofundar a análise dos dados apresentam-se, de forma detalhada, as características dos estilos de aprendizagem evidenciados na pesquisa, considerando-se os discursos dos entrevistados.

A consulta na literatura permitiu a identificação de características de aprendizagem das pessoas possuidoras do estilo divergente, dentre as quais se destacam: capacidade de imaginação, maior desempenho em atividades criativas, pessoas imaginativas e emotivas, identificação de problemas e busca de soluções, analisando a realidade. Essas características, foram evidenciadas nas falas dos gerentes possuidores deste estilo de aprendizagem, como segue:

“(...) aprendizagem é colocar em prática coisas novas, experiências de outras empresas, é uma empresa aberta às mudanças e que aceita estas mudanças(...)”.

“(...) a aprendizagem ocorre quando a gente tenta transmitir o que sabe(...)".

“(...) quando procuramos ver o que as outras organizações fazem, o que tem de bom, assimilamos e implantamos na nossa organização”.

Diante desses discursos, pode-se observar as habilidades de aprendizagem predominantes no estilo divergente, destacando-se a ênfase em colocar em prática novas idéias e a preocupação em identificar situações concretas e, por meio de sua imaginação e criatividade, colocá-las em prática nas organizações.

As pessoas possuidoras do estilo assimilador, segundo a concepção de Kolb (1997), sobressaem no raciocínio indutivo e sua maior força reside na capacidade de criar modelos teóricos. Os assimiladores estão mais preocupados com conceitos abstratos e menos preocupados com pessoas. 
Destacam-se a seguir, as falas dos gerentes com características do estilo assimilador:

“(...) para que o processo de aprendizagem realmente ocorra realizamos reuniões e debates com as equipes de alto desempenho, tentando buscar a boa vontade de todos".

“(...) a aprendizagem organizacional exige um trabalho integrado em todos os setores e estes devem trabalhar em conjunto, em parceria, onde todos trabalhem conjuntamente, transferindo o conhecimento um para o outro".

“(...) Aqui na cooperativa não tem essa de guardar a informação e o conhecimento”.

Analisando-se o discurso dos gerentes enquadrados no estilo assimilador, observa-se um paradoxo, uma vez que ambos revelaram, durante toda a entrevista, grande preocupação com as pessoas, bem como com o uso prático de teorias sólidas e consistentes no processo de aprendizagem. Os gerentes reforçaram a valorização de aspectos práticos e com a integração das diversas unidades que compõem a cooperativa analisada. Tais características se contrapõem às apresentadas pelo estilo assimilador propostas por Kolb (1997). A dimensão observação reflexiva foi predominante nos gerentes que apresentaram os estilos de aprendizagem divergente e assimilador, destacando-se a habilidade de refletir sobre novas experiências e observá-las a partir de diversas perspectivas para, posteriormente, colocá-las em prática na organização.

As características do estilo Acomodador centram-se na necessidade de realizar coisas, executar planos e de se envolver em novas experiências. Gestores com essas características tendem a se arriscar mais do que as pessoas possuidoras de características dos três outros estilos. Essas características foram evidenciadas nas seguintes falas:

“(...) a aprendizagem organizacional ocorre quando os superiores conseguem transmitir aos subordinados a maneira como a empresa deve ser conduzida".

“(...) a gente não pode ter medo de passar a informação e o conhecimento para o colega; temos que desenvolver um processo de participação".

“(...) para aprender precisamos correr riscos, aproveitando as possibilidades que existem para crescermos”.

Esse estilo de profissional tem facilidade na adaptação a circunstâncias imediatas específicas. Neste estilo de aprendizagem predominou a dimensão "experiência concreta", caracterizada pela necessidade de os gerentes se envolverem completa e imparcialmente em novas experiências. Esta dimensão é a base da observação e da reflexão. 
A grande maioria dos gerentes enquadra-se no estilo convergente de aprendizagem, que apresenta como principais características a preferência em lidar com coisas a lidar com pessoas, a tendência a serem técnicos específicos e a necessidade de aplicação prática de idéias. Os convergentes se saem melhor em situações em que há uma única resposta para cada pergunta ou problema e, segundo Kolb (1997), seu conhecimento é organizado de tal forma que, por meio do raciocínio hipotético-dedutivo, ele consegue concentrar-se em problemas específicos.

Dos sujeitos entrevistados, quatro pertencem ao estilo convergente, revelando as seguintes características, evidenciadas nas suas falas:

“(...) aprendizagem organizacional é quando a organização está aberta para normas novas que existem no mercado".

“(...) para que ocorra a aprendizagem é necessário mostrar o “como” fazer, passar a experiência para as pessoas".

“(...) a aprendizagem ocorre quando a organização dá condições para que todos tenham os instrumentos necessários para aprender”.

“(...) quando todo o mundo se tiver empenhado em buscar o conhecimento e fazer que ele se torne realidade, aplicá-lo no dia-a-dia, ocorre a aprendizagem organizacional".

Estes depoimentos evidenciam que, os gestores possuidores do estilo convergente reforçam a valorização dos aspectos técnicos e a preocupação com questões relacionadas ao compartilhamento de experiências, enfocando mecanismos práticos e objetivos no processo de aprendizagem. Os gerentes possuidores deste estilo apresentaram, predominantemente, a habilidade experimentação ativa, onde a aplicabilidade prática de teorias e idéias foi fortemente evidenciada. Estes gestores deram ênfase ao saber fazer, buscando aplicar no dia-a-dia as informações, conhecimentos e experiências adquiridas.

Visando a um melhor entendimento das características que se manifestaram nos gerentes aprendizes e a forma como repassam esse aprendizado para o contexto organizacional, buscou-se identificar, segundo o construto de McClelland (1972), as necessidades ou motivos sociais apresentados pelos gerentes.

\section{Análise dos Motivos Sociais de McClelland segundo a Percepção dos Gestores Entrevistados}

As médias da situação real e ideal dos motivos sociais, propostos por McClelland (1972), foram calculadas a partir do agrupamento das questões do instrumento 
de coleta de dados relacionadas ao motivo de poder, realização e afiliação. Observa-se, pelos resultados da pesquisa apresentados na Tabela 1, que o motivo de poder foi o que obteve uma diferença mais significativa, caracterizando o desejo dos gerentes em exercerem poder e influência sobre as outras pessoas. As médias real e ideal e a diferença das médias referentes aos motivos sociais de McClelland podem ser visualizadas na tabela a seguir.

\section{Tabela 1: Média dos Motivos Sociais de McClelland}

\begin{tabular}{l|c|c|c}
\hline \multicolumn{1}{c|}{ Motivos } & Média real & Média ideal & $\begin{array}{c}\text { Diferenças Médias } \\
\text { Real x Ideal }\end{array}$ \\
\hline Poder & 4,98 & 6,25 & 1,27 \\
Realização & 5,54 & 6,71 & 1,17 \\
Afiliação & 5,51 & 6,74 & 1,23 \\
\hline
\end{tabular}

Fonte: dados da pesquisa.

O motivo de poder que apresentou a maior diferença entre a situação real e ideal foi reforçado pelos gerentes entrevistados, como se pode observar nos seus depoimentos:

“(...) é difícil trabalhar quando tem alguém que puxa para o lado contrário (fala de um gerente)".

“(...) a grande dificuldade é conhecer cada pessoa para que ela possa produzir muito mais ... (fala de um gerente)".

Os discursos acima citados sinalizam a necessidade de mais atenção às questões ligadas ao poder, uma vez que os dados revelaram que os gestores carecem de atuação mais efetiva junto aos seus colaboradores no exercício de suas funções dentro da organização. Coda (1997) salienta que, nos resultados de pesquisas realizadas no Brasil, as críticas ao papel dos gerentes são enormes, configurando uma crise de liderança e aumentando o desafio de engajar e mobilizar os funcionários para a própria mudança e o aperfeiçoamento organizacional.

Segundo Robbins (1999) a necessidade de poder é o desejo de ter impacto, de ser influente e de controlar as outras pessoas. Os gestores entrevistados sinalizaram a necessidade de desenvolver estas características para tornar mais efetiva a atuação gerencial na organização cooperativa investigada.

O motivo social de realização foi o que apresentou a menor diferença, revelando uma proximidade entre a situação real e ideal: corrobora a preocupação da cooperativa no estabelecimento de objetivos claros e exeqüíveis: leva as pessoas a agir conforme os padrões estabelecidos e procura fazer sempre o melhor possível e com grande desejo de obter sucesso. 
Pode-se observar que o motivo de afiliação obteve a média ideal mais elevada, o que se caracteriza por um ambiente organizacional no qual predominam boas relações entre as pessoas. Este sentimento foi explicitado pelos entrevistados nas seguintes falas:

“(...) o importante é sentir-se bem no trabalho, não olhar só para o lado financeiro (fala de um gerente)".

“(...) a gente procura ter um bom relacionamento com todas as pessoas da equipe para que todos estejam envolvidos naquele trabalho e com isso se comprometerem (fala de um gerente)".

Reforça-se a importância desse motivo para as pessoas que ocupam funções gerenciais, pois manter boas relações, valorizar os sentimentos de amizade e comunicar-se com as pessoas de maneira calorosa são aspectos a serem considerados para a realização dos objetivos empresariais.

A próxima seção apresenta a inter-relação existente dos motivos sociais expostos anteriormente com os estilos de aprendizagem gerencial.

\section{Relação entre os Estilos de Aprendizagem Gerencial e os Motivos Sociais propostos por McClelland}

A Tabela 2 apresenta a relação existente entre os quatro estilos de aprendizagem e os motivos sociais de poder, realização e afiliação.

\section{Tabela 2: Os Estilos de Aprendizagem Gerencial e os Motivos Sociais de McClelland}

\begin{tabular}{l|l|l|l|l|l|l|l|l|l}
\hline \multirow{2}{*}{$\begin{array}{c}\text { Estilos de } \\
\text { Aprendizagem }\end{array}$} & \multicolumn{3}{c|}{$\begin{array}{c}\text { Motivo Social } \\
\text { PODER }\end{array}$} & \multicolumn{3}{c|}{$\begin{array}{c}\text { Motivo Social } \\
\text { REALIZAÇÃO }\end{array}$} & \multicolumn{3}{c}{$\begin{array}{c}\text { Motivo Social } \\
\text { AFILIAÇÃO }\end{array}$} \\
\cline { 2 - 12 } & Real & Ideal & Dif. & Real & Ideal & Dif. & Real & Ideal & Dif. \\
\hline Convergente & 4,40 & 6,02 & 1,62 & 5,66 & 6,59 & 0,93 & 5,17 & 6,44 & 1,27 \\
\hline Acomodador & 5,35 & 6,40 & 1,05 & 5,89 & 6,76 & 0,87 & 5,90 & 6,90 & 1,00 \\
\hline Divergente & 4,62 & 6,06 & 1,44 & 5,08 & 6,57 & 1,49 & 5,33 & 6,78 & 1,45 \\
\hline Assimilador & 5,56 & 6,56 & 1,00 & 5,53 & 6,93 & 1,40 & 5,65 & 6,86 & 1,21 \\
\hline
\end{tabular}

Fonte: dados da pesquisa.

Considerando-se os motivos sociais analisados, pode-se observar pelos dados da Tabela 2, que os estilos de aprendizagem convergente e acomodador apresentam maior diferença entre a situação real e a ideal em relação ao motivo de poder. Destaca-se, uma certa semelhança entre esses dois estilos no que se 
refere aos motivos sociais, uma vez que ambos também apresentaram a menor diferença entre a situação real e a ideal relacionada ao motivo de realização.

Os gerentes possuidores dos estilos de aprendizagem divergente e assimilador revelaram maior necessidade em relação ao motivo de realização, em contraposição ao motivo social de poder manifestado pelos gestores convergentes e acomodadores. O motivo de poder apresentou, neste caso, a menor diferença entre a situação real e a ideal.

O Gráfico 1 apresenta a evolução das diferenças das médias dos motivos sociais e os estilos de aprendizagem, constatando-se que o motivo de afiliação obteve uma diferença intermediária nos quatro estilos analisados.

\section{Gráfico 1: Evolução das Diferenças das Médias dos Motivos Sociais e os Estilos de Aprendizagem}

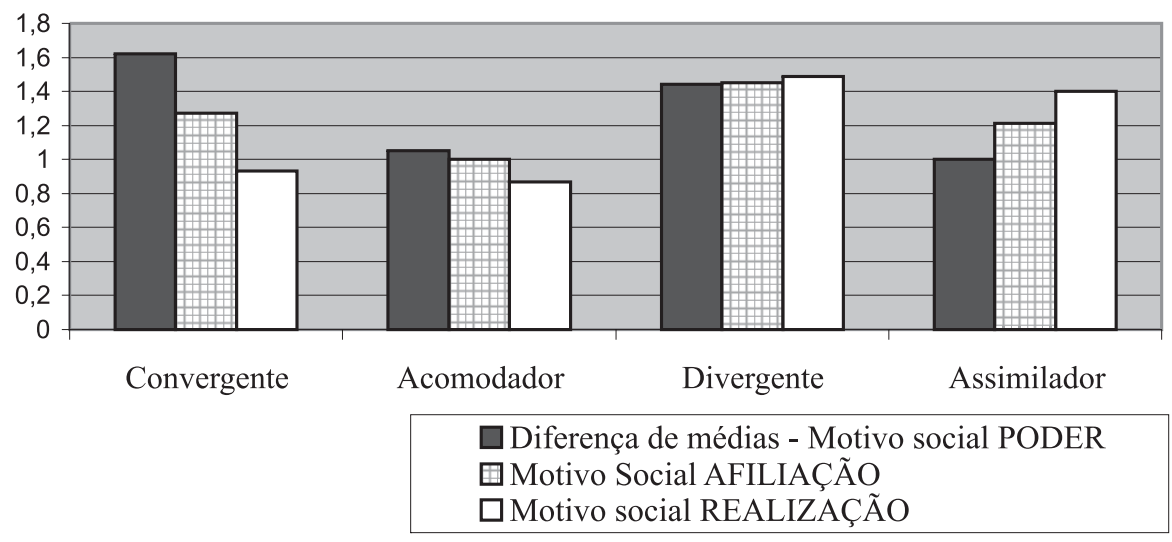

Fonte: dados da pesquisa.

Tomando-se por base a análise da situação ideal, constata-se que os gerentes possuidores do estilo convergente e assimilador revelaram uma necessidade ideal a ser buscada em termos de realização (6,59 e 6,93 respectivamente) e os gestores enquadrados no estilo acomodador e divergente idealizam, num índice superior, $o$ motivo social de afiliação $(6,90$ e 6,78). Na situação real, o motivo de afiliação obteve a média mais elevada, segundo a percepção dos gestores possuidores dos estilos de aprendizagem acomodador, divergente e assimilador. Destaca-se, entretanto, que o motivo de realização obteve a média real mais elevada na opinião dos convergentes.

Para facilitar o entendimento a Figura 3 permite visualizar os resultados obtidos e a relação entre os estilos de aprendizagem: convergente, acomodador, divergente e assimilador e os motivos sociais de poder, realização e afiliação. 
Figura 3: Relações entre os Estilos de Aprendizagem Gerencial e os Motivos Sociais

Motivos sociais
Realização
Penor diferença
Real X Ideal

É importante ressaltar que o motivo de afiliação obteve uma diferença intermediária em todos os estilos de aprendizagem analisados. Este resultado pode ser um indicativo da própria cultura cooperativista que repousa, segundo Pedrozo e Silva (1999), na interação entre pessoas, cooperados e ambiente externo à cooperativa.

Assim, este indicativo pode ser fator favorável, uma vez que os aspectos humano-comportamentais, relações próximas e amigáveis, situações de cooperação e compreensão mútua impactam significativamente o processo de aprendizagem organizacional.

\section{Considerações Finais}

O propósito deste trabalho foi o de investigar, em uma organização cooperativa, os estilos de aprendizagem gerencial sob a perspectiva de Kolb (1978), os motivos sociais evidenciados pelos entrevistados com base no construto de McClelland (1972) e verificar a relação existente entre ambos. A realização do estudo revelou a predominância do estilo convergente de aprendizagem; entretanto observa-se a presença de todos os estilos propostos por Kolb (1997) na organização analisada.

Este resultado representa um indicativo favorável ao processo de aprendizagem, pois a manifestação dos quatro estilos possibilita o envolvimento dos gestores em novas experiências, a reflexão dessas experiências sob diversas perspectivas, a criação de modelos teóricos e a utilização deles na tomada de decisões e na resolução de problemas.

Quanto aos motivos sociais, propostos por McClelland (1972), verificou-se que o motivo de poder apresentou a maior diferença entre a situação real e a ideal. 
Os depoimentos dos entrevistados sinalizaram a necessidade em exercerem uma atuação mais efetiva juntos aos seus colaboradores.

O motivo de realização apresentou a menor média, revelando uma proximidade entre a situação atual, ou seja, como realmente os gerentes se sentem hoje e a situação ideal como gostariam de se sentir.

Tomando o conjunto dos resultados e as entrevistas realizadas neste estudo, foi possível constatar a relação existente entre os estilos de aprendizagem gerencial e os motivos sociais de poder, realização e afiliação. Constatou-se que os gerentes possuidores dos estilos de aprendizagem convergente e acomodador sentem maior necessidade de poder, revelando necessidade menor de realização. Em contraposição, verificou-se que os possuidores do estilo divergente e assimilador sentem maior necessidade de realização e menor necessidade de poder.

É importante ressaltar que o motivo de afiliação obteve uma diferença intermediária em relação aos demais motivos, considerando-se os quatro estilos de aprendizagem. Entretanto convém destacar que, na análise global dos motivos sociais, foi o que obteve a média ideal mais elevada, reforçando a importância dada por pessoas que ocupam funções gerenciais as relações interpessoais e amigáveis no ambiente de trabalho.

Considerando as evidências acima, pode-se repensar o processo de aprendizagem, na organização analisada, de modo a realizar um esforço conjunto, buscando compartilhar as diversas habilidades encontradas nos gerentes investigados, da dimensão concreta à abstrata e da experimentação ativa à reflexiva. Ressalta-se, entretanto, o grande papel da organização que deve estimular e criar o clima propício ao desenvolvimento do conjunto de habilidades necessárias aos gestores para que o processo de aprendizagem realmente ocorra.

A relação entre os estilos de aprendizagem dos gerentes e os motivos sociais evidenciados na pesquisa pode contribuir significativamente para alavancar a aprendizagem no contexto organizacional, pois aspectos intrínsecos e informais ao processo, as individualidades e diferenças de cada pessoa e a forma como ocorre o aprendizado e a transferência dele para que a organização também possa aprender possibilita repensar o processo de aprendizagem organizacional à luz dessas questões.

Embora o objetivo deste trabalho tenha sido satisfatoriamente atingido, não é possível furtar-se de apresentar uma das limitações do estudo realizado. Dada a complexidade do comportamento humano, entende-se que, a classificação dos gestores de acordo com determinados estilos e motivos sociais não deve ser considerada de maneira estanque e definitiva, nem como um reducionismo ou simplificação, mas como uma forma de compreendê-lo melhor. 
Espera-se que essa pesquisa contribua no sentido de provocar reflexões que remetam ao desenvolvimento de outros estudos, envolvendo outras variáveis que possibilitem melhor entendimento da complexidade desse tema. Sugere-se a ampliação deste estudo, utilizando-se outras fontes de evidência e a sua realização em outros segmentos organizacionais para (re)pensar, (re)ver, (re)discutir e (re)criar uma nova visão e analisar as relações que se estabelecem de forma mais ampla e complexa, possibilitando novo olhar sobre a aprendizagem no contexto organizacional.

\section{Artigo recebido em 12.05.2004. Aprovado em 26.06.2004.}

\section{Referencias Bibliográficas}

Aguiar, M. A. F. de (1988).

Psicologia aplicada a administração (2a ed.). São Paulo: Atlas, 1988.

Antonacopoulou, E. (2001).

Desenvolvendo gerentes aprendizes dentro de organizações de aprendizagem. In M. Easterby-Smith., J. Burgoyne, \& L. Araujo (Orgs.). Aprendizagem organizacional $e$ organização de aprendizagem. São Paulo: Atlas.

Argyris, C., \&

Schon, D.A. (1978).

Organizational Learning: a theory of action perspective. Reading, Massachusetts: Addison- Wesley.

Bernardes, M. E. B. (1999).

Learning Organization em empresa brasileira: um estudo de caso. Dissertação de Mestrado, Universidade Federal de Minas Gerais, Belo Horizonte, MG.

Boyett, J. H., \&

Boyett, J. T. (1999).

O guia dos gurus: os melhores conceitos e práticas dos negócios. Rio de Janeiro: Campus.

Caravantes, G., \&

Pereira, M. J. L. (1985).

Aprendizagem organizacional versus estratégia de mudança organizacional planejada: um confronto crítico. Porto Alegre: FAPERGS.

Coda, R. (1997).

Psicodinâmica da vida organizacional - motivação e liderança (2nd ed.). São Paulo: Atlas.

Dodgson, M. (1993, Summer).

Organizational learning: a review of some literatures. Organizational Studies, 14 (3), 375-394.

Fleury, A., \&

Fleury M. T. L. (1997).

Aprendizagem e inovação organizacional: as experiências de Japão, Coréia e Brasil (2a. ed). São Paulo: Atlas. 
Garvin, D. A. (1993, July/August). Building a learning organization. Harvard Business Review, 71(4), 78-92.

Gil,A.C. (1999).

Métodos e técnicas de pesquisa social (5a ed). São Paulo: Atlas.

Kim,D. (1998).

O elo entre a aprendizagem individual e a aprendizagem organizacional. In D. A. Klein. A gestão estratégica do capital intelectual. Rio de Janeiro: Qualitymark.

Kolb, D. A.,

Rubin, I. M., \&

McIntyre, J. M. (1978).

Psicologia organizacional: uma abordagem vivencial. São Paulo: Atlas.

Kolb, D. A(1997).

A gestão e o processo de aprendizagem. In K. Starkey. Como as organizações aprendem: relatos dos sucessos das grandes empresas. São Paulo: Futura.

McClelland, D. C. (1972).

A sociedade competitiva: realização e progresso social. Rio de Janeiro: Expansão e Cultura,

Morgan, G. (1996). Imagens da organização. São Paulo: Atlas.

Nakayama, M. K.,

Binotto, E., \&

Estivalete, V.F. B. (2002).

Os estilos de aprendizagem gerencial facilitam a aprendizagem individual, coletiva e organizacional? Revista Análise, 13(2), 311-327.
Pedrozo, E., \&

Silva, T.N. (1999).

Cooperativa, uma organização diferenciada rumo à sustentabilidade. Revista Análise, 10(2), 47-74.

Quivy, R., \&

Campenhoudt, L. V. (1992).

Manual de investigação em ciências sociais. Portugal: Gradiva Publicações.

Robbins, S. P. (1999).

Comportamento organizacional (8a ed.). Rio de Janeiro: Livros Técnicos e Científicos Editora S.A.

Romani, C., \&

Dazzi, M. C. (2002).

Estilo gerencial nas organizações na era do conhecimento. In M. T. Angeloni (Coord.). Organizações do conhecimento. São Paulo: Editora Saraiva.

Schein, E. (1996).

Culture: the missing concept in organization studies. Administrative Science Quartely, 41(2), 229-240.

Senge, P. (1990).

A quinta disciplina: arte, teoria e prática da organização de aprendizagem. São Paulo: Best Seller.

Senge, P. (1998).

A quinta disciplina (2a ed.). São Paulo: Best Seller.

Souza, E. L. P. de (1978).

Clima e cultura organizacionais: como se manejam e como se manifestam. São Paulo: Edgard Blucker. 
Sweringa, J., \&

Wierdsma, A. (1995).

La organización que aprende. Wilmington, USA: Addison-Wesley.
Yin, R. K. (2001).

Estudo de caso: planejamento e métodos (2a ed.). Porto Alegre:

Bookman. 